\section{J.R. Moehr}

School of Health Information Science University of Victoria

Victoria, BC, Canada

\title{
History of Medical Informatics
}

\section{The Quest for Identity of Health Informatics and for Guidance to Education in it - The German Reisensburg Conference of 1973 Revisited}

\begin{abstract}
Purpose: To review the minutes of the invitational workshop for defining the contents and approaches to education in and the professionalization of health informatics, which took place in Germany thirty years ago; To provide context for the meeting and assess its impact.

Approach: The minutes resulting from the meeting were translated into English, and the literature attesting to the effects of the meeting was compiled in a literature review and commented on.

Results: The meeting had profound effect in Germany, providing a model for several tiers of educational initiatives, and for professional recognition of the field of medical informatics. These were refined over the last thirty years and persist to this day. At the international level, the impact can be traced to the IMIA recommendations for education in health/medical informatics. More recent initiatives at defining the content of health informatics education did not result in fundamentally different models.

Conclusion: One may assume then that the contents of education in medical/health informatics are well defined. The methods of education deserve greater attention.
\end{abstract}

formed the basis for pertinent work of the sponsoring learned societies, the Society for Medical Documentation and Statistics (Gesellschaftfür Medizinische Dokumentation und Statistik e.V., GMDS) as it was then called ${ }^{2}$, and the Society for Informatics ${ }^{3}$ (Gesellschaft für Informatike.V., GI). The former is an association of academics-mostly with medical orientationadvancing medical documentation, statistics and epidemiology. The latter is an association of computer scientists.

The minutes were never formally published but turned out to be very influential - in Germany and beyond defining the contents of education in health informatics at multiple levels and a starting point for a number of related initiatives. Many of the questions raised then keep being raised again and again nowadays, without fundamental change in the answers.

On the occasion of the thirtieth anniversary of this meeting, it seems therefore appropriate to make the results of the meeting available to a wider audience and to retrace its effects. The minutes - known to insiders in Germany as the "Reisensburger were distributed to participants and

\footnotetext{
1 The terms 'health informatics' and 'medical informatics' are used interchangeably here in the sense defined by Shortliffe in [1]

2 Currently, this society is called "Deutsche Gesellschaft für Medizinische Informatik, Biometrie und Epidemiologie (GMDS) e.V."

3 The term 'informatics' is used here as synonymous with 'computer science' in accordance with the choice of terminology of the GI.
} 
Protokoll" - are therefore offered here in an English translation with some comments. The comments will address:

The approach;

The background;

Comments on the meeting as such;

Effects in Germany; and

International effects,

and then proceed to a discussion and conclusions.

\section{TheApproach}

The author was one of the participants of the Reisensburg conference and involved in compiling the minutes from the notes of the six recorders, including his own, before a final edit done by P. L. Reichertz. The translation brought back reminiscences, which over the time span of thirty years may or may not have been accurate. Therefore the translation and these comments were shared with other participants of the meeting ${ }^{4}$ and their comments incorporated in the final version, just as those received from two former chairs of International Medical Informatics Association's (IMIA) Working Group 1 (Education) who directed much of the developments in health informatics education referred to here ${ }^{5}$. This commentary also made use of the referenced literature. However, a detailed assessment of the relevance of the Reisensburg meeting to all pertinent European and international developments was not possible, given the time frame for this project. So the literature is a selection of work that the author was personally exposed to.

In the translation, care was taken to stick to conveying the spirit of the minutes. This involved, e.g., referring to 'informatics' rather than 'computer science' in accordance with the decision of the Society for Informatics not to chose the designation 'Society for Computer Science'. Similarly, the term 'medical informatics' is used in the translation of the minutes rather than 'health informatics' because the term was used at the meeting in an encompassing sense as defined by [1]. In this commentary the author also uses the term 'health informatics' since it has become in many areas the more accepted term for the comprehensive field. Also, the various German scientific societies are referred to by translated names and the German names are given in brackets at first appearance. Some back ground information on German concepts and practices at the time are included in the next section, hoping that they will further understanding as well as assessment of the meeting, its significance, and the direction of the discussions.

\section{Background}

The GI had been founded just four years before the meeting in question, in the Fall of 1969. At that time, a framework for academic curricula in informatics had been prepared with support of existing learned societies for mathematics and communication technology: the Society for Applied Mathematics and Mechanics (Gesellschaft für Angewandte Mathematik und Mechanik e.V., GAMM) and the Communication Technological Society (NachrichtenTechnische Gesellschaft e.V., NTG). This framework included three pillars of informatics: theoretical informatics, technical informatics and practical informatics. About $75 \%$ of the curriculum were devoted to thiscore of computer science. The remaining $25 \%$ were assigned to an application field. Alternatives for the application field vary from university to university and may include such disciplines as engineering, commerce, mathematics or medicine [2].
On the medical side, the GMDS had in the fifties evolved from a subgroup of the German Society for Documentation (Deutsche Gesellschaft fuer Dokumentation e.V., DGD) which was devoted to medical record and medical literature documentation, and had been incorporated as an independent organization in 1966.

In 1969, the German Institute for Medical Documentation and Information (Deutsches Institut für Medizinische Dokumentation und Information, DIMDI) had been founded in Cologne as a federal agency for medical literature and morbidity documentation. Also, in 1970, a core of education in biomathematics, statistics and medical documentation had become a mandatory part of the education of medical students in an amendment of the regulation for the accreditation of physicians (Ärztliche Approbations Ordnung).

At the same time, in the Fall of 1969 , Peter L. Reichertz had returned to Germany after several years in the USA, from the University of Columbia Missouri, to become director of a "Division for Medical Informatics" (Abteilung Medizinische Informatik) at Hanover Medical School [2].

From within the GMDS, Reichertz immediately set out to gather colleagues around himself interested in "electronic information processing". On March 3, 1970, at the inaugural meeting of this group, he had, among others, suggested to develop a program for education in what he at that time already called "Medizinische Informatik". At the next meeting, in July, he presented a framework for education [2]. Over the next few years, this group, which quickly grew to about 200 persons, evolved into a "Fach-

\footnotetext{
The assistance provided by G.W. Brauer, Munich, W. Gaus, Ulm, R. Gnatz, Munich, and H.K. Selbmann, Tübingen, is gratefully acknowledged. The reviews of a draft version of the paper by D. Protti, Victoria, and R. Haux, Innsbruck, are very much appreciated.
} 
bereich Medizinische Informatik" within the GMDS". "Section for Medical Informatics" may be an appropriate translation. This group developed a number of research initiatives carried on in regular meetings in areas such as laboratory data processing, or free text analysis, among others. The development of educational programs for medical informatics was one of the initiatives pursued with high priority.

Reichertz also initiated a dialogue with representatives of computerscience in the GI. This led to convincing both societies, GI and GMDS, that a joint workshop devoted to defining a framework for education in medical informatics would be appropriate. The meeting convened in 1973 at the Reisensburg was the result.

The Reisensburg is a former stronghold on the banks of the Danube with a history dating back to preRoman times. After a recent renovation it was then run by an "International Institute for Scientific Cooperation" in support of scientific conferences. It is now associated with the University of Ulm and provides a very pleasant work environment for small conferences ${ }^{7}$.

In order to understand some of the debates taking place in May 1973, it is worth knowing that the German education system distinguishes strictly between a scientific education - in principle conveyed only by Universities and some other institutions of higher education - and vocational education conveyed by numerous other institutions without a strong research orientation. Also, in those days, the German education system did not have a

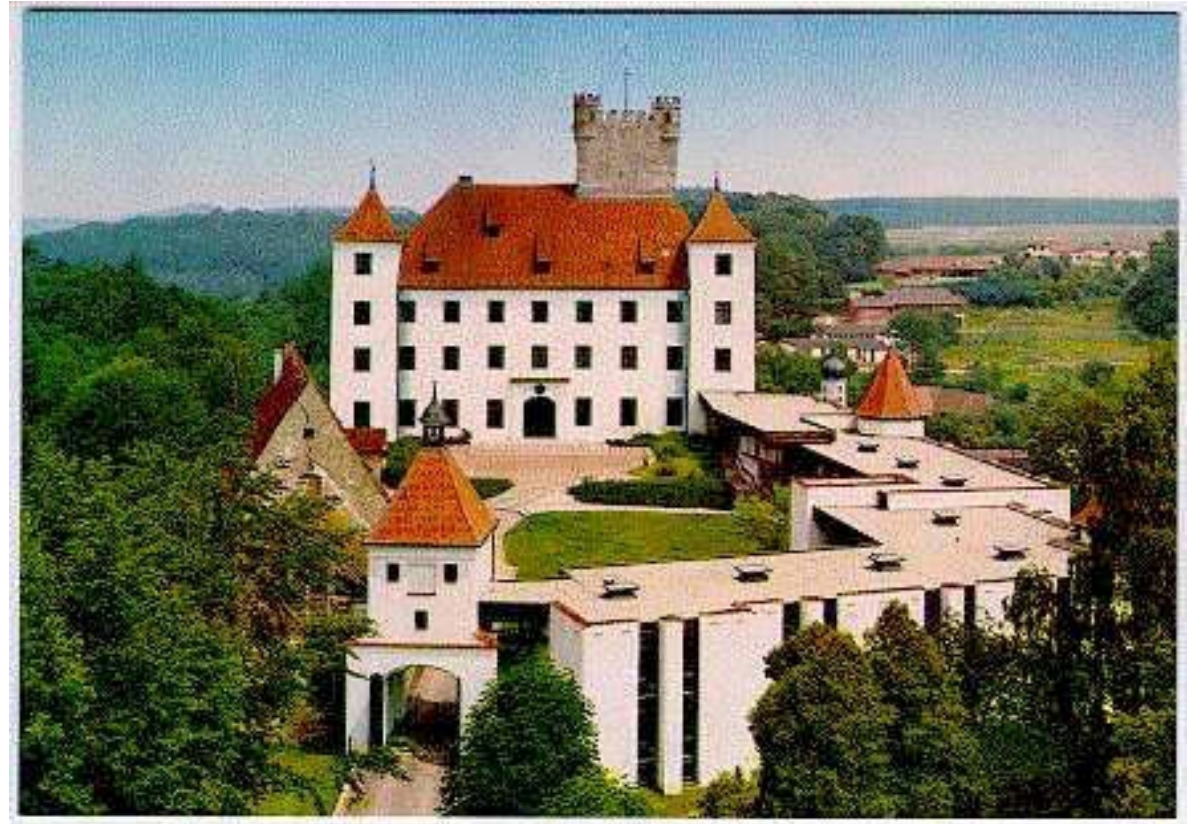

Fig.1. Reisensburg, Germany.

universally applicable layered structure distinguishing undergraduate from graduate education, and a Masters level from a $\mathrm{PhD}$ level in graduate and post-graduate education. Different disciplines had different vertical structures leading to such degrees as a diploma in informatics, or a state examination in medicine. Doctoral degrees were attainable on top of such degrees and were discipline specific, such as a doctoral degree in engineering (Dr.-Ing.) or a doctoral degree in medicine (Dr. med.), both being dissertation-based. It is also worth noting that there was no graduation at the level of a bachelor's degree in Germany in those days.

Vocational training is typically offered by "Fachhochschulen", perhaps best translated as "vocational colleges". At this level, and in association with Universities, training programs for "Medical Documentation Assist- ants" had just been initiated. These were 2 and 3 year programs for health record librarians. Also, in the previous Fall of 1972 a program for Medical Informatics had just been instituted at one of the vocational colleges, the Heilbronn Polytechnic ("Fachhochschule Heilbronn" "). This was the initiative of Dr. Walter Hellerich, then Rector of the Polytechnic, and was independent of the GMDS/GI group. The fact that this program led to the title "Diplom-Informatiker der Medizin" brought this initiative of a vocational college too close for comfort to the Holy Grail of academic education for the knights assembled around King Peter at the Reisensburg castle. The initiative in Heilbronn was therefore perceived bluntly as a "problem" After all, proper academic education in informatics led to a title of "DiplomInformatiker", a degree, which is equivalent to a Masters degree in computer science.

\footnotetext{
${ }^{6}$ The author served for many years as Secretary of this Section of Medical Informatics.

7 Wissenschaftszentrum Schloß Reisensburg der Universität Ulm: http://idw-online.de/public/pmid-66489/zeige_pm.html ; accessed 030728

8 Currently, the preferred translation into English is "University of Applied Science Heilbronn" http://www.fh-heilbronn.de/fhhn/fhhn.Webserver accessed 030726

9 This choice of terminology in the minutes may in part be the responsibility of the author who drafted the minutes.
} 


\section{Comments on the meeting as such}

The meeting was intense, lasting from early morning until late at night for two days, and concluding in the afternoon of the third day. It was tightly managed by P. Reichertz as Chair, and the minutes are a tribute to his ability to keep this group of strong headed individuals on track, even though many issues could not definitively be resolved.

Another strong trait was the sense of urgency, which determined the agenda, and which were very much discussed in a polarity between attendees who identified themselves with computer science, and those who perceived themselves as medical informaticians more than as medical doctors - which all of them were. It is also noteworthy that it was an all male gathering, without representation from such areas as nursing or medical record librarianship and their predominantly female constituencies.

This polarity between computer science and medical informatics may have been historically motivated, including a good deal of serendipity in the process that led up to the meeting. But it put education in medical informatics on a definite track with two rails, which had several immediate as well as long term effects.

For one thing, a conspicuous difference in style and vision between the two groups was remarkable. The computer-scientists took a minimalist approach, defining a subset of their demanding field that might be manageable by medical students or professionals. Three tracks were specified, with a very modest hint that if individuals were up to it, they could tackle all three, and would probably benefit from it.
The medical informaticians, on the other hand, specified an approach that included some biomedical fundamentals, but beyond that delved into directions that are not part of core medical education:

- Methods Critique of Medical Thought and Decision Processes; - Man and Environment;

- Hospital Organization and Management; and

- Organizational Structures in Health Care, Legal Issues.

The important aspect about this is that a new entity was consciously created, something more than the union of two subsets on informatics and medicine. It was also anticipated that these subjects would have to be taught by medical informaticians, since they are rarely available in existing medical or informatics curricula.

Another noteworthy aspect was the conscious attention on the part of both camps to a vertical and horizontal symmetry in the education endeavors. This had to deal with incompatibilities between the vertically defined main components, the framework for education in informatics (computer science) and medical education. There was also a serious attempt to define educational opportunities from the vocational through to the more demanding academic level. There are even modest suggestions of a vertical permeability between the levels, traditionally considered incompatible in their demands and orientations, and a solid commitment towards strong complementarity, if not interchangeability, between the graduates originating from roots in informatics or in medicine, or beyond.

This educational framework was based on a vision of professional activities and responsibilities, and their grounding in existing professional structures. In this respect, there was again a strong contrast between the perceptions of the informaticians - who argued as proponents of a theoretical science, and with some apprehension of the medical professional world, which they perceived as antiquated if not obsolete-and the medical informaticians - who argued from the perspective of medicine, very much a practical science [3] and the environment of their professional identity.

\section{Effects in Germany}

The Reisensburg meeting - documented in the minutes - had multiple conceptual and practical effects in Germany which persist to this day. These include:

- Educationin medicine as application area for informatics;

- Educationininformatics for medical students;

- Framework for the integrated education of specialists in medical informatics;

- $\mathrm{NATO}^{10}$ - sponsored "Advanced Course Informatics and Medicine"; - Certificate "Medical Informatics"; and

- Additional qualification "Medical Informatics" for medical specialists.

\subsection{Education in medicine as application area for informatics}

Immediately after the Reisensburg meeting, several university programs in informatics started offering medicine as application subject - among the several other application disciplines. These included such universities as the University of Hamburg, Munich, Erlangen, etc. A current website lists seven universities with an informatics faculty offering such subjects as "medicine" or "theoretical medicine"

${ }^{10}$ The North Atlantic Treaty Organization (NATO) sponsored several high tech conferences, such as the one referred to here. 
for their students, including the three already mentioned ${ }^{11}$.

\subsection{Education in medical informatics for medical students}

Another effect was incorporation of medical informatics into the education of medical students in 1978, with another change of the regulations for the accreditation of physicians. This subject was offered to varying degrees of intensity, depending on the university. For instance, at the University of Münster F. Wingert [4] offered a demanding very formal and theoryoriented course, while the University of Heidelberg included an optional four times 2 hours of health information system demonstrations in an 'ecological course', in which such subjects as population health, or clinical trials were offered as competing options [5]. But at least medical informatics was on the map of medical education from then on, in the form of mandatory exposure of all students and in addition to more formal education in statistics and documentation.

\subsection{Framework for the integrated education of specialists in medical informatics}

Perhaps one of the most important and original contributions of the conference was the creation of a vision of a new type of professional, the 'health informatician' or 'health informaticist' ('Medizin-Informatiker') and the specification of an integrated curriculum which was more than the union of a subset of medicine and informatics [6]. This provided a welcome framework for the Heilbronn Polytechnic who had already established a formal link with the University of Heidelberg. In keeping with the multidisciplinary orientation of the framework developed at the Reisensburg, the college comple- mented existing faculty including mathematicians, physicists, chemists, and engineers with more mathematicians and engineers (but with an informatics orientation and education), and very notably, an economist. The medical subjects and biomedical statistics were covered by faculty from the University of Heidelberg ${ }^{12}$ and the German Cancer Research Centre in Heidelberg. With the university connection and a solid number of broadly ranged faculty, the basis to provide an integrated education with the goal of producing 'Medical Informaticians' or 'Diplom-Informatikerder Medizin' had been created [6-10].

The program has meanwhile graduated more than "1024 graduates" [11]. Sixty seven out of 446 responding to this recent survey had attained a doctoral degree, among them such key contributors to the field of health informatics as Dr. Reinhold Haux, who among other is founding Rector of the new University of Medical Informatics and Technology in Innsbruck, Tyrol, Austria.

Currently, the previously mentioned website lists three more universities in Germany offering "medical informatics" as an integrated specialized curriculum, in addition to Heidelberg/ Heilbronn. There are also two additional vocational colleges offering integrated curricula of medical informatics ${ }^{11}$.

\subsection{NATO - sponsored Advanced Course Informatics and Medicine}

Again, on the initiative of P.L. Reichertz, a NATO-sponsored Advanced Course on Informatics and Medicine was organized and conducted in English at Hanover Medical School in 1975. It included an international selection of computer scientists, as well as medical informaticians as faculty, and attracted an international audience. The proceedings, published by Springer Verlag in 1977 [12], probably constitute a second prototype of a textbook for medical informatics, after the one published by R.S. Ledley in 1965 [13]. Unfortunately, the Reichertz/Goos texthad comparatively little impact, since the English language made it poorly accessible for students in Germany, without on the other hand generating much readership in other countries.

\subsection{Certificate Medical Informatician}

Another prominent suggestion arising from the Reisensburg meeting was to issue a certificate that would be available to professionals in health informatics, regardless of a background in informatics, medicine, or even other areas. The main thrust of this proposal was to attest operational qualification and to pave the way to essentially situating people pursuing a leadership career in health informatics at the level of a chief of service in a medical specialty (e.g., Chief of Medicine, Chief of Surgery).

Such a certificate was in fact instituted in 1978 with support from the two sponsoring societies, GI and GMDS [14]. Since then, it is commonly cited as a prerequisite for leadership positions in health informatics, including academic positions at universities, and it has been updated several times [15, 16]. Having been awarded the certificate is normally also a prerequisite for training others who aspire to obtain the certificate or the additional qualification 'Medical Informatics' (see below).

Prerequisites for the certificate include comprehensive knowledge and experience in medical informatics,

11 www.thieme.de/viamedici/infopakete/zusatzausbildung/infopaket_medizinische_informatik.html, accessed 030727

12 From 1977 to 1986, the author was the representative of the University of Heidelberg responsible for the health informatics program. 
informatics, medicine ${ }^{13}$, biometrics and economics, as well as at least 5 years of 'operational qualification' in pertinent institutions-normallydirected by aholder of the certificate. Operational qualificationhas toincludeat least one clinical study and involvement in some projects touching on the other areas, with the possibility to pursue a focus of emphasis, such as medical imaging or the responsibilities of a Chief Information Officer in a medical institution. Proof in the form of projectreports, publications, etc., and arecommendation of the director of the organization where the candidate completed his/her operational qualification are required. Amultidisciplinary commission with members appointed by GI and GMDS reviews applications, maymake recommendations forcomplementary activities and initiatives of the candidate, and decides on whether the certificate should be granted to an applicant. The certificate is considered a very demanding qualification ${ }^{11}$.

The 2002 Annual Report of the GMDS states that 150 certificates have been issued [17]. This may be considered a relatively modest number, given that by this time the Heidelberg/ Heilbronn curriculumalone had already issued over 1000 graduates, not to mention the graduates from the other programs specifically geared to the education of health informaticians, or the many informatics programs offering a minor in medicine. However, not all graduates of these programs end up working in health informatics positions, do not do so continuously, or may not aspire to leadership positions [11].

It may also be of interest to note that the certificate idea was picked up by other groups within the GMDS in that certificates were eventually offered for medical biometrics (since 1981) and medical epidemiology (since 1992) ${ }^{14}$.

\subsection{Additional qualification "Medical Informatics" for medical specialists}

As the minutes show, the issue of recognizing competence in medical informatics for physicians was a brainchild of the medical establishment and not of the group assembled at the Reisensburg. The suggestion to issue the license to carry a professional designation in addition to a medical specialization is in line with established practice of the medical profession in Germany. The degrees of freedom for advertising for medical (and other ) professionals are tightly and narrowly regulated.E.g., only defined terms may be used on a sign identifying an office or a professional, and they may only be presented in prescribed format and layout. A specialist for ear, nose and throat diseases (ENT) may be identified as "Facharzt für Hals- Nasen- und Ohrenkrankheiten". An optional additional qualification for such a specialist might be 'speech therapy'. It was at this level of an additional qualification which can only be obtained by accepted specialists, that the specialization in "medical informatics' was envisioned by the medical professional organizations.

At the Reisensburg conference, this concept was only partially embraced. On the one hand, it provided an argument for the need for constructs such as the certificate, which would be open to informaticians as well as medical professionals. Given the perceived need for comprehensive education and extensive operational qualification, the certificate would have been preferred at the level of a full medical specialization, i.e., that of the specialization for ENT in the above example, or that of a full specialization in such areas as 'radiology' or 'nuclear medicine'.

Recognition of specializations and additional qualifications is the responsibility of 'physicians' chambers' ("Ärztekammern") which are organized in accordance with obsolete state boundaries, and governed by a general framework of regulations for the medical profession. All of them now recognize the additional qualification in medical informatics, which was introduced gradually in the mid to late seventies. When it became apparent in the nineties that a surplus of physicians had been produced, the additional qualification medical informatics turned into a welcome alternative for physicians who had reasons to pursue their profession outside direct patient care, e.g., in the form of positions in science or industry, or as part time occupation.

As a consequence, several institutions started offering courses leading to the additional qualification 'medical informatics" ${ }^{15}$. One of them claims to have graduated more than 350 physicians ${ }^{16}$. The qualification requires a minimum of 2 years of clinical work and a minimum of $1 \frac{1 / 2}{2}$ years of work in medical informatics as operational qualification, normally under the supervision and direction of a holder of the certificate for medical informatics. Therefore the education is typically spread over a series of week end seminars that can be completed over a period of a few years. The Heidelberg/

\footnotetext{
${ }^{13}$ Medicine in this context is understood as encompassing knowledge of the institutions, professionals and the processes, rules and regulations governing them, i.e. synonymous with health care.

${ }^{14}$ www.gmds.de/texte/weiterbildung.html, accessed 030727

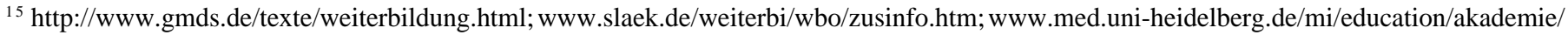
mi-faqs_dt.htm; http://www.meb.uni-bonn.de/cgi-in/medevent/sideentrance.pl?EVENT=389\&LANG=englisch; http://www.med.uniheidelberg.de/mi/education/akademie/akademie_dt.htm; http://www.mibeg-medizin.de/html/mibb.htm; accessed 030727

${ }^{16}$ www.mibeg-medizin.de/html/mibb.htm accessed 030727
} 
Heilbronn site is also offering a masters degree in 'Medical Information Management' (Masterstudiengang Informationsmanagement in der Medizin, IM) which is available to physicians ${ }^{17}$.

In summary, it can be said that the meeting had a profound impact on education in health/medical informatics in Germany. The principles worked out were later updated several times and a more streamlined version of the education in health informatics was devised [18], maintaining, however, the organization along the two tracks of informatics, i.e., computer science, and medicine, and the vertical layering of different careers with different demands.

\section{International Effects}

The effects of the Reisensburg conference were not limited to Germany, however. And although the author is not in a position to provide a systematic overview of all effects on other European countries (compare, e.g., [19-26]) and the rest of the world, an attempt will be undertaken to draw attention to some effects that may be important from the perspective of the North American health informatics scene.

One of the most important results of the Reisensburg conference was the creation of a new breed of professionals, the 'healthinformatician'. The contemporary initiatives in the USA, e.g., in the form of educational programs funded by the National Library of Medicine since the late sixties, were of a different kind $^{18}$. They were associated with a number of different academic institutions, including, e.g., medical schools, or departments of computer science, biomedical statistics, or biomedical engineering. The US programs were typically graduate or post graduate programs producing each a few highly qualified individuals with a variety of specialized skill sets that varied between fostering institutions in accordance with the primary orientation of these [19]. In contrast, the specialized programs in Germany were oriented to educating individuals towards a new profession, for which a defined set of core skills was conveyed. Such a line of thought was pursued toward the end of the seventies by the ACM SIGBIO (Association of Computing Machinery Special Interest Group Biomedical Computing) [27, 28], but the concept was not, to the knowledge of the author, realized in a comprehensive way.

One program that was inspired by the ACM SIGBIO deliberations was that of the University of Victoria in Victoria, B.C., Canada [29-31]. Here a program for "Health Information Science' was developed in the early eighties. It also took explicit notice of the model developed in Heidelberg/Heilbronn through close interaction between the author and the founding Director of the Program, Denis Protti. The author later joined this program, which accounted for some direct influence of the experience in Heidelberg/Heilbronn, and hence of the concepts developed at the Reisensburg conference. But until very recently, the program at the University of Victoria remained the only program in Canada with a strong healthinformatics orientation.

Other programs providing specialized comprehensive education in medical informatics, starting at the undergraduate level, such as the Bachelor of Science in Health Information Management of the University of Alabama ${ }^{19}$, appeared much later in the USA, somewhat concurrent with the evolution of the American Association of Medical Record Librarians (AAMRL), then American Medical Record Association (AMRA), to the American Health Information Management Association (AHIMA) in 1991. This, their mission and the course content put these programs more in the vicinity of the programs for medical documentation assistants in Germany.

Another prominent effect of the conference, the inclusion of a mandatory exposure to medical informatics in the education of medical students seems to be still lacking in North America despite very strong advocacy in the early eighties [32].

It seems fair to state then, that the direct influence of the Reisensburg meeting in North America was slight, if not imperceptible. This observation is not surprising in principle, since mainstreamevolutions in non-English speaking countries are rarely acknowledged in North America. But it is remarkable in the face of another evolution.

In 1999, IMIA WG1Educationissued 'Recommendations of the International Medical Informatics Association(IMIA) on Education in Health and Medical Informatics' [33]. These recommendations do indeed bear a strong imprint of the Reisensburg conference, which is not surprising since their development by an international committee was headed by R. Haux, former Chair of IMIA WG1 and, among other, a prominent leader in the development of the German initiatives for health informatics education. The IMIA recommendations also bear strong resemblance to the earlier German recommendations, also issued under the leadership of Haux [18]. They maintain the parallelism of IT users and $\mathrm{HI}$ specialists (referred to as 'health and medical informatics specialists'), of medical and informatics (i.e.,

\footnotetext{
17 http://www.mi.fh-heilbronn.de/ accessed 030727

18 Compare, e.g., http://www.nlm.nih.gov/ep/T15Training.html; accessed 030727

19 http://main.uab.edu/show.asp?durki=3397 ; accessed 030728
} 
computer science) education tracks and the progression frombasiceducation to doctoral level education, which are mapped to a three dimensional structure.

This similarity between the Reisensburg concepts and the IMIA WG1 recommendations is in contrast to the persistence of qualitatively different programs in the United States, the orientation of which is more determined by the orientation of their academic environment than by a common blue print, such as the IMIA WG1 recommendations [33]. These programs and their diversity are a testimony to the fact that there are indeed potential alternatives to the concepts developed thirty years ago in Germany. Prominentinfluences on the programs offered in the United States cover a broad range frombusiness, economics and managementsciencetocognitivescience, computational linguistics and intelligence, to genomics. And while the programs supported by the $\mathrm{NLM}^{18}$ are typically graduate, doctoral and post doctoral programs, it may be a legitimate question to ask whether the diversity, which seems obviously desirable at the upper echelons of education in health/medical informatics is complete and able to serve into the future the requirement of society and the profession that serves it.

\section{Discussion}

Given the observations above, it is no wonder that the question regarding desirable core competencies keeps being asked. In addition the question of desirable peak competencies may be worth raising. And if one raises these questions one should also ask how to approach the answers.
At the Reisensburg, likely tasks and roles that a health informatician should be able to accomplish were the basis for deliberations. A similar effort was recently undertaken independently in Canada $^{20,21}$. In this approach three tracks were differentiated:

- Applied Health Informatics (AHI)

- Research and Development Health Informatics (RDHI)

- Clinician Health Informatics (CHI).

For the Applied health informatics track alone, 11 Macro-Roles (e.g., CIO, Director, Analyst, Internal Consultant) were defined and 30 challenges identified that people filling these roles have to cope with (e.g., IT/ IM Strategic Planning, Procurement). From this, a list of 184 Micro-Roles (sub-functions or tasks, e.g., Identify Requirements for Technology) that health informaticians have to fulfill was derived to address these challenges. This then led to the identification of 203 Skills and 167 Knowledge elements (e.g.: Needs Analysis Method, Listening Skills, Requirements Definition and Analysis; Knowledge of Personal Productivity Applications and their Capabilities, Knowledge of Specific Environment) that will give them required capabilities. This was then taken as the basis to define a curriculum that imparts the necessary skills, knowledge, and experience based on 22 identified knowledge categories.

The effort took several years and was supported by major funding. It involved extensive stake holder consultations, video conferences and work shops. The effort did foster the development of at least two graduate programs in health informatics in Canada ${ }^{22,23}$. But the results are qualitatively not substantially different from the concepts that emanated from the Reisensburg conference 30 years ago. And in the light of the Canadian effort, the efficiency of the Reisensburg conference is certainly remarkable.

Another alternative that might be worth pursuing is not analytic but deontological. E. Kluge, Univ. of Victoria, has developed a Code of Ethics for Health Information Professionals that was subsequently adopted by IMIA on recommendation by its Working Group 'Data Protection in Health Information Systems' (WG4) ${ }^{24}$. This code of ethics is based on a system of ethical principles, from which duties of health informatics professionals are derived. These duties include:

- Subject centered duties (e.g., towards the subject of databases),

- Duties towards health care professionals,

- Duties towards institutions/ employers,

- Duties towards society,

- Self regarding duties, and

- Duties toward the profession.

An analysis of these duties should yield an ethically founded catalogue of skills and competencies that a health informatician must have in order to fulfill these duties. It would be interesting to explore what skills, competencies and attitudes one could derive in this way.

Yet a different approach was recently pursued by I. Kohane ${ }^{25}$ who presented the following question to the fellows of the American College of Medical Informatics (ACMI): "What question in a test would you expect/ want $70 \%$ of the graduates of our training programs to be able to answer?" This question was answered on a

\footnotetext{
20 http://hi.uwaterloo.ca/hi/CIHR_Model_Curricula.htm; accessed 030728

21 http://www.informatics-review.com/thoughts/pointing.html ; accessed 030728

22 http://www.cs.uwaterloo.ca/health_info/Waterloo_Graduate_Specialization.htm; accessed 030728

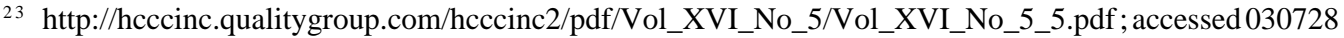

24 http://www.imia.org/English_code_of_ethics.html; accessed 030728

25 http://www.chip.org/people/isaackohane.html The author gratefully acknowledges the permission to reference I. Kohane's evolving collection.
} 
voluntary basis by fellows of the ACMI. The range of answers was obviously determined by the range of programs that are in existence - and the decision of their faculty to answer the question. But it is interesting that of the 19 questions collected by Jul 12, 2003, five were genomics-oriented and the resthealth informatics-oriented. Within the health informatics group, three touched on high level information systems strategies, the rest on methodological issues, including data base and humaninterface design, and algorithmic issues for such purposes as automated classification, data mining, computer representation of guidelines. Given its efficiency, this approach might warrant further pursuit, in particular since it might answer the question of peak competencies in addition to that of basic and core competencies.

On another level, it is, however, remarkable that the issue of content has received comparatively greater attention than the issue of education methodology. And although most mature programs have contributed novel and creative contributions on how to teach health informatics [3439], discussions in the context of the generation of new programs keeps returning to the issue of content. Unfortunately, content is likely to only affect the knowledge and skills conveyed. In order to affect other key aspects of education, such as the attitudes of those educated, one has to affect the manner of teaching and its contribution to the educational outcomes. The issue is probably well illustrated by the following excerpts from one of the questions that were submitted to I. Kohane's ${ }^{25}$ collection: "You are hired by a forward-looking moderate-size academic health care center to introduce clinical decision support and quality/safety measures into their care delivery system. Your first attempt to do so, a stand-alone guideline system"... "is only used by $5 \%$ of all clinicians, and then only sparingly. What actions would you take at this point ... .?" In the answers to such questions lie some real challenges to health informatics. It may be in this area that contributions are currently most necessary. Some have argued for a long time that health informatics is more about social issues and change management than it is about technology [40]. Others have drawn attention to the need for sociological approaches to making health information systems work [41, 42] and for explaining why they sometimes do not [43]. Yet others have provided abundant proof of the impact of educational psychology and cognitive science on the improvement of health information systems [44].

But there are other phenomena that require us to change the manner in which we teach: The requirement of distant, dispersed populations to be educated, including not only specialists but providers in the widest sense, and even patients/health care clients. How will we take advantage of Telematics to deliver health care, evidence-based medicine, continuing education in health care, no to mention education in health informatics?

Given all this, it may be time to reconsider whether the pursuit of a double track of medicine/health sciences and informatics/computer science is still an adequate basis for education and academic research in health informatics. Even the participants of the Reisensburg conference acknowledged multidisciplinarity beyond that scope. Maybe the analysis of desirable peak competencies would provide further needed guidance.

\section{Conclusion}

The Reisensburg conference and the initiatives that it engendered had major impact in Germany and beyond.
These are certainly one of the major legacies that we owe to Peter L. Reichertz who was taken from us prematurely in 1987 at the age of only 54. But in light of the continued quest for identity of health informatics and for guidance to education in it, and in view of new challenges, it may be time to try different approaches. The quest for the contents of education in health informatics, in terms of knowledge and skills may have been answered thirty years ago. Improvements beyond that, produced by renewed efforts, may be merely incremental. But the mode of how and through whom to educate in such a way that acceptable and accepted systems, and sustainable and sustained support of answers to important practical and theoretical questions result, may continue to elude us unless we shift our emphasis from the content to the methodology of education in health informatics.

\section{Acknowledgements}

The author thanks R. Haux for suggesting this project and providing one of the rare surviving copies of the original minutes of the Reisensburg meeting, and D. Protti and R. Haux for reviewing a draft version of the paper.

\section{References}

1. Shortliffe EH, Fagan LM, Wiederhold G, Perreault LE, editors. Medical Informatics: Computer Applications in Health Care and Biomedicine. Heidelberg, New York: Springer; 2000.

2. Moehr JR. Teaching Medical Informatics Teaching on the Seams of Disciplines, Cultures, Traditions. Medical Informatics and Education Special Issue, Methods Inf Med 1989;28:273-80.

3. Wieland W. Diagnose: Überlegungen zur Medizintheorie. Berlin: De Gruyter; 1975.

4. Wingert F. Medizinische Informatik. Stuttgart: Teubner; 1979.

5. Moehr JR, Sawinski R. On Priming Medical Students in Medical Informatics. Methods Inf Med 1985;24:149-54.

6. Moehr JR, Leven FJ, Rothemund M. Formal Education in Medical Informatics. - Review of Ten Years' Experience with a Specialized University Curriculum. 
Methods Inf Med 1982;21:169-80.

7. Moehr JR. Education of Specialists in Medical Informatics: The Heidelberg/ Heilbronn Experience in the Federal Republic of Germany. Med Inform 1984; 9: 299-300.

8. Leven FJ. Curriculum for Medical Informatics at the University of Heidelberg/ School of Technology Heilbronn. Methods Inf Med 1994;33(3):262-7.

9. Haux R, Leven FJ. Twenty Years Medical Informatics Education at Heidelberg/ Heilbronn: Evolution of a Specialized Curriculum for Medical Informatics. Methods Inf Med 1994;33(3):285-9.

10. Frey W, Haux R, Leiner F, Leven FJ. Medical Informatics Heidelberg/Heilbronn: Graduates' Experiences and Job Situation. Methods Inf Med 1994;33(3):290-8.

11. Knaup P, et al. Medical Informatics Specialists: What are their Job Profiles? Results of a Study on the First 1024 Medical Informatics Graduates of the Universities of Heidelberg and Heilbronn. Methods Inf Med. In press 2003.

12. Reichertz PGG, editor. Informatics and Medicine - An Advanced Course. Heidelberg: Springer; 1977.

13. LedleyR. Use of Computers in Biology and Medicine. New York: McGraw-Hill; 1965.

14. Deussen P, et al., editors. Zertifikat Medizinischer Informatiker. Stuttgart, New York: Schattauer; 1978.

15. Moehr JR, Bertram HJ, Deussen P, Eickel J, Koehler CO, Koeppe P, et al., editors. Durchfuehrungsrichtlinien zum Zertifikat MedizinischerInformatiker. 2nd ed. GMDS Mitteilungen, ed. GMDS. Stuttgart, New York: Schattauer; 1979.

16. GMDS. Zertifikat Medizinische Informatik. Durchfuehrungsrichtlinien. Informatik, Biometrie und Epidemiologie in Medizin und Biologie 1993;24:28-38.

17. Heitmann KU, editor. GMDS Jahresbericht 2002. Köln: Deutsche Gesellschaft für Medizinische Informatik, Biometrie und Epidemiologie e.V; 2002.p. 276.

18. Haux R, Dudeck J, Gaus W, Leven FJ, Kunath H, Michaelis J, et al. Recommendations of the German Association of Medical Informatics, Biometry and Epidemiology on Education in Medical Informatics. Methods Inf Med 1992;31:60-70.

19. Moehr JR. Training and Education in Medical Informatics. In: van Bemmel JH, Ball MJ, Wigertz O, editors. MEDINFO 83. Amsterdam: North Holland; 1983.

20. Moehr JR, Protti DJ, Salamon R, editors. Medical Informatics and Education. Special Issue of Methods Inf Med 1989;28. Stuttgart: Schattauer.

21. Moehr JR, Protti DJ, Salamon R. Medical Informatics and Education - Review of an IMIA Working Conference. In: Barber B,
Cao D, Qin D, Wagner G, editors. MEDINFO 89. Amsterdam: North Holland; 1989. p. 931-5.

22. Moehr JR, Protti DJ, Salamon R. Medical Informatics and Education: Progress, Problems, and Priorities. In: van Bemmel JH, Zvarova J, editors. Knowledge, Information and Medical Education, Selected Papers from the IMIA International Conference on Medical Informatics and Medical Education; Sept. 3-7, 1990; Prague, Czechoslovakia. Amsterdam: North Holland; 1991. p. 3-10.

23. Committee of Ministers, Council of Europe. Recommendation No. R(90) 21 of the Committee of Ministers to Member States on Training Strategies for Health Information Systems. In: Hasman A, Wainwright P, Klar R, Sosa M, editors. Education and Training in Health Informatics in Europe. State of the Art Guidelines - Applications. Amsterdam: IOS Press; 1995.

24. Hasman A, Wainwright P, Klar R, Sosa M, editors. Education and Training in Health Informatics in Europe. State of the Art Guidelines-Applications. Amsterdam: IOS Press; 1995.

25. Hasman A, Albert A. Education and Training in Health Informatics: Guidelines for European Curricula. Int J Med Inf, 1997;45:91-110.

26. Haux R, Swinkels W, Ball M, Knaup P, Lun $\mathrm{KC}$, editors. Health and Medical Informatics Education: Transformation of Health Care through Innovative Use of Information Technology in the $21 \mathrm{st}$ Century. Proceedings of the 6th International Conference on Health and Medical Informatics Education; August 1416, 1997; Newcastle, Australia. Int J Med Inf 1998;50:1-300.

27. Duncan KA, Austing RH, Katz S, Pengov RE, Pogue RE, Wasserman AI. Health Computing: Curriculum for an Emerging Profession. Proceedings of the ACM 78. 1978. p. 277-85.

28. Duncan KA. A Model Curriculum for a Doctoral Level Program in Health Computing. New York:ACM; 1981.

29. Protti D, Fisher P. Health Informatics: The Evolution of the Program at the University of Victoria. In: van Bemmel JH, McCray AT, editors: 1996 IMIA Yearbook of Medical Informatics. Stuttgart: Schattauer; 1996. p. 135-139.

30. Anglin CR. Health Information Scienc At UVic - The Student Perspective. Methods Inf Med 1989;28(4):285-91.

31. Protti D. Health Information Science at the University of Victoria: The First Ten Years. Methods Inf Med 1994;33(3):268-72.

32. AAMC. Physicians for the 21 st Century (The GPEP Report). Washington DC:
Association of the American Medical Colleges; 1984

33. Haux R. Recommendations of the International Medical Informatics Association (IMIA) on Education in Health and Medical Informatics. Methods Inf Med 2000; 39(3):267-77.

34. Moehr JR, Berenji GR, Green CJ, Kagolovsky Y. Project-based Teaching in Health Informatics: A Course on Health Care Quality Improvement. In: Patel VL, Rogers R, Haux R, editors. MEDINFO 2001. London: IOS Press;2001. p. 1061-5.

35. van Bemmel JH, Sollet PCGM, Grashuis JL.Education in Medical Informatics in the Netherlands - a Nationwide Policy and the Erasmus Curriculum. Methods Inf Med 1989;28(4):227-33.

36. Hasman A. Description of a Block Course in Medical Informatics. Methods Inf Med 1989;28(4):239-42.

37. Leven FJ. Software Engineering Education in Medical Informatics. Methods Inf Med 1989;28(4):295-303.

38. Schneider W. Computers in a Human Perspective: an Alternative Way of Teaching Medical Informatics to Health Professionals. Methods Inf Med 1989;28(4):313-20.

39. Protti DJ. Teaching Hospital Informat Systems by Simulating What Really Happens. Methods Inf Med 1989; 28(4):281-4.

40. Protti DJ, Haskell AR. Managing Information in Hospitals: $60 \%$ Social, $40 \%$ Technical. Proc IMIA Working Conference on Trends in Hospital Information Systems. Amsterdam: North Holland Publishing; 1992. p. 45-9.

41. Anderson J. Clearing the Way for Physicians' Use of Clinical Information Systems. Commun ACM 1997;40(8):83-90.

42. Anderson J, Aydin C, Jay S. Evaluating Health Care Information Systems. Methods and Applications. Thousand Oaks, CA: Sage; 1994.

43. BalkaE. Getting the Big Picture. The MacroPolitics of Information System Development (and Failure) in a Canadian Hospital. Methods Inf Med 2003;42(4): 324-30.

44. Patel V, Kushniruk AW, Yang S, Yale JF. Impact of a computer-based patient record system on data collection, knowledge organization and reasoning. J Am Med Inform Assoc 2000;7(6):569-85.

Address of the author:

Jochen R. Moehr

School of Health Information Science

University of Victoria

Victoria, BC, Canada

E-mail: JMoehr@UVIC.CA 